\title{
An Example of Connections between the Mathematics Teacher's Conceptions and Specialised Knowledge
}

\author{
Álvaro Aguilar-González ${ }^{{ }^{*}}$, María Cinta Muñoz-Catalán ${ }^{2}$, José Carrillo ${ }^{3}$ \\ ${ }^{1}$ Universidad de Oviedo, Oviedo, SPAIN \\ 2 Universidad de Sevilla, Sevilla, SPAIN \\ ${ }^{3}$ Universidad de Huelva, Huelva, SPAIN
}

Received 11 February 2018 - Revised 14 August 2018 - Accepted 26 September 2018

\begin{abstract}
The motivation for this study is to understand the professional knowledge that a teacher displays in her classroom when she teaches mathematics classes. To this end, our goal is to describe the possible relationships of the subdomains of Mathematics Teacher's Specialised Knowledge (MTSK) model and the Conceptions about Mathematics Teaching and Learning (CMTL) that are integrated in it. This article presents a position on professional knowledge, the methodological design used has been an interpretative approach with a case study design of a 5th grade teacher in Primary Education, and some results which exemplify how these relationships have been identified and analyzed, and how they have helped to explain and understand the knowledge that the teacher mobilizes in her classroom. Finally, we express how this study can be used for teacher training in mathematics.
\end{abstract}

Keywords: mathematics teacher's specialised knowledged, conceptions about mathematics teaching and learning, teacher's knowledged, professional knowledge

\section{INTRODUCTION}

As explained by Ball, Lubienski and Mewborn (2001), teachers and their knowledge have been the focus of many investigations since the publication of the third edition of the Handbook of Research on Teaching. In this Handbook, it is argued that there is a lack of a program in educational research on the study of "teachers cognitive understanding about content knowledge and the relationships between that understanding and the instruction that teachers provide to their students" (Shulman, 1986, p. 25) and it is indicates that teacher's knowledge is one of the most important facts that affects a class.

The research literature has devoted much attention to the knowledge that teachers should possess to teach. Ponte (2012) points out that the identification of the knowledge necessary for the teacher's professional practice and access to the conceptions that structure it are not enough, it is also necessary to understand the nature of this knowledge as an inseparable element of the teacher's action.

This is when different models of the mathematics teacher's knowledge begin to emerge (e.g. Mathematics for teaching (Davis \& Simmt, 2006), Knowledge Quartet (Rowland, Huckstep \& Thwaites, 2005), Mathematical Knowledge for Teaching (MKT) (Ball, Thames \& Phelps, 2008) and the Mathematics Teacher's Specialised Knowledge (MTSK) (Carrillo-Yáñez et al., 2018). These established theoretical models are useful tools for teachers who wish to reflect on their professional knowledge. Each model offers a different perspective that enables us to approach professional knowledge.

Our focus in this paper is to understand the characterization of the knowledge that is put into play in the practice of a primary school teacher (who has had 20 years of experience in primary education, was dissatisfied with her performance in teaching mathematics and felt a lack of it), and how this characterization allows us to deepen the conceptions about the teaching and learning of mathematics evidenced.

(C) 2019 by the authors; licensee Modestum Ltd., UK. This article is an open access article distributed under the terms and conditions of the Creative Commons Attribution License (http://creativecommons.org/licenses/by/4.0/).

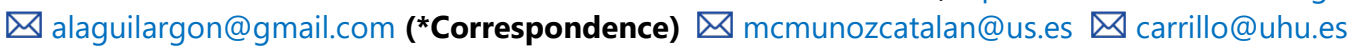




\section{Contribution of this paper to the literature}

- The Mathematics Teacher's Specialised Knowledge (MTSK) model is a theoretical proposal that recognizes the potential of describing a body of knowledge that only makes sense for the mathematics teacher, and is, in turn, a methodological tool for analyzing different mathematical practices through its categories.

- The Mathematics Teacher's Specialised Knowledge (MTSK) model eliminates the problems of delimitation between subdomains that other knowledge models have defined, by assuming the specialised character for all the subdomains. This is an advance with respect to other models.

- The Mathematics Teacher's Specialised Knowledge (MTSK) model considers the beliefs of the teacher at the core of the model; the fully integrated study of the relationships between beliefs and knowledge is an advance.

\section{LITERATURE REVIEW}

\section{Why we use MTSK Model?}

Firstly, MTSK model extended to all knowledge subdomains its specialised character (compared to the MKT knowledge model that only takes as a subdomain of specialised content knowledge), in other words, considers specialization as the core of the mathematics teacher's knowledge in all its domains, subdomains and categories and does not refer to any other science or profession.

Secondly, MTSK model is rooted in mathematics itself, leaving out aspects of general pedagogy and psychology. The authors understand that these aspects are relevant for the teacher's understanding, but are not specific to mathematics.

In third place, integrates the Conceptions about Mathematics Teaching and Learning (CMTL). The MTSK model arises in a research group with a tradition of research in the different theoretical positions regarding the differentiation between beliefs, conception and knowledge. Thus, in the MTSK, they are represented in the center of the diagram with dotted lines (see Figure 1).

Interest in the study of the teacher's conceptions is not recent. In fact, in the research literature on teacher education, conceptions tend to be a main focus of attention, since they play an important role in understanding the behaviour of teachers during their instruction (e.g. Cooney \& Shealy, 1994; Ernest, 1988; Thompson, 1984, 1992). Regarding the relationship of conceptions with knowledge, there are different positions. Some researchers understand conceptions as part of the PCK of teachers (e.g., Ball, 1990; Fennema \& Franke, 1992; Gess-Newsome, 1999). Others, like Thompson (1984, 1992), make an explicit distinction between knowledge and beliefs.

Finally, MTSK model covers all levels of education. In our case, we will use the model in an analysis of a 5 th grade Primary School class in polygon teaching.

\section{Mathematics Teachers' Specialised Knowledge (MTSK)}

This knowledge model appears as an advance on the studies proposed by Shulman (1986) and Ball et al., (2008). It takes into account the specialised nature of the teacher's knowledge in a comprehensive manner to all the subdomains that comprise it.

In Flores, Escudero and Carrillo (2013), the subdomain Specialised Content Knowledge (SCK) from Ball, et al., (2008) is analyzed and concludes that it is controversial to consider that subdomain as exclusive to the mathematical domain. The specialization of MTSK enables it to distinguish itself from general knowledge of pedagogy (knowledge of pedagogy and psychology in general, which is also part of the professional knowledge of mathematics teachers). That is to say, the MTSK is specialised in the subject of teaching mathematics. It has a duality: it is a theoretical proposal that models the core knowledge of the professional knowledge of the mathematics teacher and it is, in turn, a methodological tool that allows us to analyze different practices of the mathematics teacher through its categories (Flores, Escudero \& Aguilar, 2013).

Figure 1 shows the scheme and the subdomains of which the model is composed. 


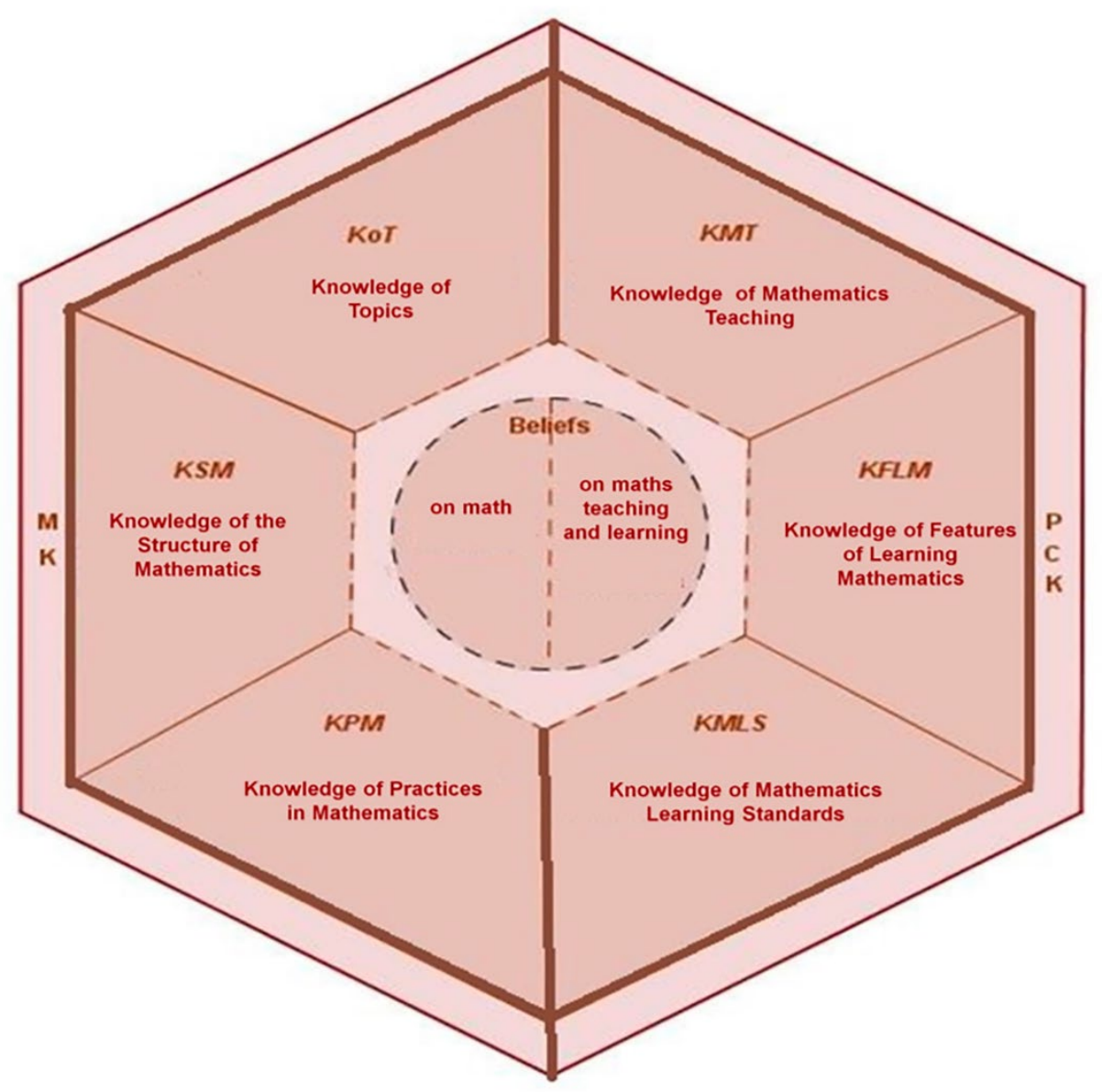

Figure 1. Subdomains of the MTSK (Carrillo-Yáñez et al., 2018)

This model maintains the differentiation proposed by Shulman (1986) and followed by Ball et al., (2008) in two dimensions of knowledge: Mathematical Knowledge (MK) and Pedagogical Content Knowledge (PCK). In turn, it is divided into subdomains, and within these they are composed of categories. The nature of the subdomains is summarized below. For reasons of extension, we have made a selection of the aspects contained in each of them. Focusing mainly on those subdomains and categories that have emerged in the analysis of the classroom session: The Knowledge of Topics (KoT) is defined as a well-founded and deep knowledge of mathematical content. It consists of the following categories: phenomenology and applications, which is the knowledge of models attributable to a topic, as well as the uses and applications of a mathematical topic (Escudero-Ávila, Carrillo, Flores-Medrano, Climent, Contreras, \& Montes, 2015); definitions, properties and their foundations, comprises the knowledge to describe or characterize a concept, the properties of a mathematical object, and the knowledge that the teacher has about the bases, foundations or completeness of the use of a property; representation registers, refers to knowledge about the different ways in which a topic can be represented, including the notation and the mathematical language associated with such representations (Mora, Climent, Escudero-Ávila, Montes, \& Ribeiro, 2016); and procedures, where we consider the knowledge that the professor has about conventional and alternative algorithms (How is it done?), the sufficient and necessary conditions to proceed (When can it be done?), the fundamentals of the algorithms (Why is it done like that?), and the characteristics of the resulting mathematical object associated with a topic (characteristics of the result) (Vasco, 2015). For example: Teacher knows the properties and elements of the polygons that will be used to define it.

The Knowledge of the Structure of Mathematics (KSM) comprises the knowledge of connections between subsequent and previous content, including how mathematics is internally connected (Montes, Aguilar, Carrillo, \& Muñoz-Catalán, 2013). For example: When teacher relationships between the concepts of flat and threedimensional shapes.

The Knowledge of Practices in Mathematics (KPM) integrates hierarchical organization and planning as ways of proceeding in the resolution of problems, forms of validation and demonstration, role of symbols and formal language uses, processes associated with problem solving as a way of producing mathematics, particular practices 
of mathematical work (such as modeling), as well as necessary and sufficient conditions to generate definitions. For example: When teacher uses her knowledge of Mathematical Practice in the very procedure of defining (clear, ordered and precise expression), knowing what a definition is and what its characteristics are, because she knows how knowledge is explored and generated in mathematics and what are the elements with which mathematics is done.

The Knowledge of Mathematics Teaching (KMT) integrates knowledge of mathematics and its teaching. Without being mathematical knowledge in itself, the teacher requires the latter in order to develop it. KMT involves, knowing different strategies that enable the teacher to foster the development of procedural or conceptual mathematical abilities, knowing ways of representation (Shulman, 1986) to make specific content understandable, knowing resources that allow the teacher to help their pupils find out, through manipulation, certain mathematical concepts or examples that manage to awaken in their pupils the intuition of some concepts, making use of powerful examples and knowing what to do to help the student progress. The category Knowledge of strategies, techniques and tasks for the teaching of mathematical content comprises knowledge about the mathematical potential that certain sequences of activities can have. It also comprises tasks, strategies or didactic techniques that teachers consider powerful in the approach to mathematical content and at a particular teaching moment. For example: The choice of rich images, which include relevant, irrelevant and incorrect attributes with respect to the definition of polygon, highlights aspects of their knowledge of differentiation between definition and image of the concept.

The Knowledge of Features of Learning (KFLM) is the knowledge of how mathematical content is learned. The main focus is not on the pupil, but on the teacher's knowledge of the mathematical content as an object of learning. It comprises the category of Knowledge of the strengths and difficulties associated with learning mathematical content. The increasing amount of cognitive research on pupil learning, developed in recent decades, has produced many results focused on the identification of conceptions, errors, obstacles, and students' difficulties and their mathematical thinking (Even \& Tirosh, 2008). For example: Teacher is aware of the difficulties that her students have in uniting a series of characteristics such as the definition of polygon.

The Knowledge of Mathematics Learning Standards (KMLS) includes the knowledge of the contents proposed in the curricular structures, and contemplates aspects of knowledge derived from scientific journals, research groups and professional associations.

\section{Why we use CMTL?}

Firstly, if we want to understand the characterization of the knowledge that is put into play in the practice of a primary school teacher and how this characterization allows us to deepen or infer the conceptions about the teaching and learning of mathematics evidenced by the teacher. In our case, the results obtained from Climent (2005) from the same teacher, invited us to study this case in depth mainly because there were changes in different aspects of his professional development, mainly there was a change in her conceptions of their vision of school mathematics, especially with regard to what and for what purpose she teaches.

Secondly, her 20 years of experience in Teaching in Primary Education, and participation in a collaborative research group had made her reflect and she had questioned her knowledge of her practice to work with Problem Solving methodology.

Finally, she was a good informant contrasted, because when she had been analyzed, Climent (2005) obtained interesting results regarding her knowledge.

\section{Conceptions of the Primary school teacher on the Teaching and Learning of Mathematics}

With regard to the study of the beliefs of the teacher on the Teaching and Learning of mathematics we understand that these are intrinsically linked to the knowledge of the teacher, that is, they permeate it.

The research literature emphasizes that teacher education should focus on the development of beliefs (e.g., Cooney \& Shealy, 1994; Ernest, 1988; Ponte, 1992; Thompson, 1992; Wilkins \& Brand, 2004), due the fact that they influence the behavior of teachers in their instruction (e.g., Thompson, 1984, 1992). Although beliefs are difficult to change (Pajares, 1992), there is research where future teachers, after participating in an undergraduate course, modify them (e.g., Wilkins \& Brand, 2004). Therefore, they are considered a fundamental aspect in the teacher's understanding.

Thompson (1992) also indicates the differences between beliefs and knowledge through two perspectives. First, beliefs can be considered with varying degrees of conviction, while knowledge is generally not thought of in this way. In addition, beliefs are not consensual, but knowledge is. It also addresses the important relationship between knowledge and beliefs. "To look at research on mathematics teachers' beliefs and conceptions isolated from mathematics teachers' knowledge will result in an incomplete picture" (Thompson, 1992, p. 131). However, the study focuses on the relationship and connection between these two aspects that can be explored. 
Making use of the theoretical basis presented in the theses of Carrillo (1998) (from which the CMTL instrument was derived) and Contreras (1999), we decided to consider beliefs as an element so close to conceptions that it makes no sense to distinguish them, as claimed by Philipp (2007); Maasepp and Bobis (2015); Zoitsakos, Zachariades and Sakonidis (2015). There are no significant benefits for the understanding of the nature of the professional knowledge of the mathematics teacher, since both beliefs and conceptions are linked in the same way to knowledge. This enables us to approach the study of both constructs, as well as the relationships between them. Conceptions are an element different from knowledge, but intimately linked to it in such a way that it permeates the knowledge that the teacher has in each of the subdomains.

The CMTL instrument developed by Climent (2005) was designed from the instrument for the analysis of the teacher's conceptions on the teaching of mathematics (Carrillo, 1998), which shows its potential to study the concepts of secondary school teachers. This CMTL instrument respects the distinction of the four didactic tendencies presents, serving as general indicators its abbreviations within the categories (traditional, TR; technological, TE; spontaneous, E; and research, I). And it groups them into the following categories (for reasons of extension, only one example of each category is shown to help the reader understand the nature of the categories, as well as the numbering). To see the complete instrument read Climent (2005):

- Methodology: where the following aspects are considered: The activity in the classroom; Praxis; Sources of information; Individual differentiation; Use of manipulative materials; Objectives; Programming.

Table 1. Example of Conception on Methodology (Activity in the classroom)

TR1: Classroom activity is characterized by iterated repetition of typical exercises.

TE1: The classroom activity is characterized by the repetition of exercises that try to reproduce the logical processes and, coherently, the study of errors by the students.

E1: The exercises are replaced by a non-reflective experimental activity. There is a tendency to put methods, resources... into play.

11: Students usually face situations for which they do not have a given resolution process (problematic situations, whether they be problems or investigations, often contextualised into real problems).

- Conception of school mathematics: where the following aspects are considered: Orientation; Contents; What's like?; Purpose.

Table 2. Example of Conception of school mathematics (Orientation)

TR9: The subject is oriented exclusively towards the acquisition of concepts and rules.

TE9: Both the concepts and rules and the logical processes that underpin them are of interest.

E9: Concepts are not so much about concepts as procedures and the promotion of positive attitudes (towards school work and citizenship).

19: The acquisition of concepts, the development of procedures and the promotion of positive attitudes towards the subject itself, school work in general and as a citizen are all of interest, and the subject and school work determine the specific weight of each of the components mentioned.

- Conception of learning: where the following aspects are considered: Learn; Type and shape; Processes; Argumentational importance; Teacher-student-matter interaction; Type of grouping; Dynamizer; Aptitude; Attitude.

Table 3. Example of Conception of Learning (Learn)

TR13: It is assumed that learning is carried out, using memory as the main resource, by overlapping units of information. TE13: Learning continues to be conceived as memoristic, organized internally according to the structural logic of the subject. E13: Learning takes place when the learning object, which emerges randomly from the context, has meaning for the learner. 113: Learning objects not only have meaning, but also the ability to be applied in different contexts from where they were learned, thus acquiring a mobile character through a conceptual mesh.

- Role of the student: where the following aspects are considered: Participation in the didactic design; Transfer key Teaching-Learning; What are they doing?

Table 4. Example of Conception of Role of the student (What are they doing?)

TR27: Student does not intend to process the information that comes from the teacher, neither in form nor in substance.

TE27: The student's confidence in what the teacher has said, induced by the technique used, prevents him or her from questioning the substance of the content.

E27: The dynamic environment in the classroom allows the student to communicate his or her experiences and feelings with the teacher and other classmates.

127: Student maintains a critical attitude towards the information that is mobilized in the classroom.

- Role of the teacher: where the following aspects are considered: What and how does he do it?; Validation of the information. 
Table 5. Example of Conception of Role of the teacher (What and how does he do it?)

TR28: Teacher transmits the learning contents verbally, by explaining what is reflected in the textbook, making a literal reproduction of it. Acts as a content specialist.

TE28: Teacher organizes the learning content, which is transmitted through exposure, using organizational/expository strategies that aim to be attractive. Acts as a content and didactic design technician.

E28: Due to its marked humanistic character and specialist in group dynamics, it induces the student to participate in the activities it promotes, analysing the reactions and responses to its proposals.

129: Teacher provokes the curiosity of the student by conducting his or her research towards the achievement of learning. As an interactive experimenter of content and methods, he is obliged to analyse processes in the context of the classroom (action research).

The categories are numbered consecutively to make the descriptors that compose them operational. These descriptors can be included within the didactic tendencies previously mentioned, having a different nature, according to the didactic tendency in which it is located.

\section{METHODOLOGY}

In this article (although it is part of a larger research) we respond to the following research objectives with information from the analysis of a single session Video-recording 1 [V1] (there are 8 in total) of a video-analyzed class is shown a Primary Education teacher's 5th grade class. We present the first video recording because it includes a concept that will be required throughout the sessions:

a) Identify and understand elements of the different subdomains of the teacher's MTSK in relation to the teaching of polygons, as well as the possible relationships between those subdomains.

b) Detect the conceptions about the teaching and learning of the teacher's mathematics and their relationship with the subdomains of specialised knowledge for the teaching of polygons.

In order to satisfy both objectives, we position ourselves in an interpretative paradigm (Bassey, 1999), since we are concerned with understanding, discovering, and interpreting reality, instead of testing hypotheses previously formulated (Merriam, 1988). There are three perspectives that characterize a paradigm: ontological, epistemological and methodological (Lincon \& Guba, 1985). Regarding the ontological perspective, we consider that professional knowledge is a social phenomenon constructed by the teacher as information provider, their interaction with the different contexts where their professional work is carried out and their commitment to improve their practice in relation to mathematics. Consequently, we do not believe that we can access this knowledge in a totally objective way.

Regarding our epistemological perspective, understood as the relationship between what is known and what can be known (Santos, 2002), we consider that our results are an interpretation that, as researchers, we make of the teacher's knowledge. This knowledge enables us to approach reality and identify the foundation of that knowledge (Muñoz-Catalán, 2009).

For its part, the methodological perspective refers to how we build knowledge with respect to reality, that is, how we can obtain such knowledge. It is in this section where the researcher asks themselves how they should proceed and why they make the decisions they do. The design of this research corresponds to a case study, in which we have thoroughly analyzed a singularity in depth, obtaining the data in the natural environment of the classroom (Bassey, 1999).

Case studies can be described from two perspectives: the aims pursued or the results obtained (Stake, 2000, 2005). Based on the former, our study is intrinsic, which seeks to deepen and gain a greater understanding of the case itself, and to understand the particular case. The case provides information on the teacher's specialized knowledge, which can serve as a basis for contrasting the results with other cases and investigations, in order to understand the nature of the phenomenon itself. We also affirm that it is a descriptive study, because it seeks to describe and understand the reality observed from the actions of the teacher in her classroom. This allows us to construct interpretations of the teacher's specialized knowledge regarding the mathematical content of study.

\section{Information collection and Analysis Tools - Relationships between Sub-domains}

We conceive analysis as a process of interpretation (Blumer, 1969), in which the researcher's ability to recognize and attribute meaning plays a crucial role, stemming both from his or her immersion in the data and from his or her knowledge and professional experience. This is what is known as theoretical sensitivity (Strauss \& Corbin, 1994).

The analysis of the sessions was approached in three phases: transcripts (Transcripts as a first level of analysis that suppose a construction carried out by the researcher of the reality observed according to his research objectives); organization and structuring of each session where we divide the session into different 
episodes/subepisodes (Organizing and structuring the data using the Schoenfeld model (1998a; 1998b; 2000); preparation of reports by session (where MTSK and CTML knowledge descriptors are identified).

For the analysis of this session, two instruments of analysis have been used: the MTSK (author, year), with the domains, subdomains and categories described above, and the CMTL instrument, Climent (2005) which was used to analyze the teacher's homonymous conceptions.

In the session analyzed, three types of connections have been identified throughout the video recording: - Firstly, for an episode to affirm that two (or more) subdomains of knowledge are related, we identify signs or indications (Flores, Escudero \& Aguilar, 2013) that help us to interpret what knowledge the teacher has revealed, and with that identification we relate that knowledge in a complementary manner.

- Secondly, for us to be able to say that a subdomain of knowledge is related to a conception, we must be able to infer that conception acts permeating the subdomain of knowledge in the episode, allowing us to access a more detailed understanding of the teacher's knowledge.

- In third place, to relate a conception with two (or more) subdomains of knowledge, this conception should guide the analysis so that these relationships help to understand, and highlight, how that conception is put into action, permeating the two (or more) knowledge subdomains.

With it a report has been obtained that reflects our interpretation on what knowledge and/or conceptions, the teacher has brought into play in her implementation of the didactic unit on polygons. The report has been prepared using an interpretative approach since our main objective was to take a close look at the data in order to find structures and relationships of meaning that were not apparent in the text (Kvale, 1996). Furthermore, each piece of identified knowledge or concept has been coded through its corresponding subdomain acronym, and with a consecutive number to make it easier for the reader to find its subsequent location (eg. KoT1, KoT2, I8, I24... See Appendix for more information). This numbering is continuous throughout all the sessions. If a certain piece of knowledge is in different video recordings, the number assigned to it in the video recording in which it appeared for the first time is respected. Information units have also been included, coded with their location in the transcript by means of the transcription lines ([V1. Line 6-14]).

With the previously described MTSK descriptors and the three types of connections that have been established, a graph of internal MTSK relationships is shown (Figure 3) which contains, on one side, the indicators of knowledge and conceptions identified throughout the session, expressed by the assigned codes at the end of each session. The indicators of each subdomain, either of knowledge or of conceptions (located in the center of the figure of the model), have been drawn in circles with two different sizes: the smaller one is used for knowledge or conceptions that have been identified in two or fewer occasions; the largest (three or more) is for the knowledge or concepts that have been used more regularly throughout the session. This serves as visual support to identify which subdomain or subdomains of knowledge or conceptions have been predominant during the session. If any subdomain or conception is not identified in the analysis, it is not shown with circles. However, predominance is not only highlighted on the basis of the size of the circle, but also in terms of the number of connections arriving at or leaving a specific subdomain.

\section{ANALYSIS RESULTS}

In this section, the descriptors that were interpreted in the analysis of the video recording of the teacher when she taught math classes are shown. The descriptors referring to MTSK and indicators used to analyze Conceptions about Mathematics Teaching and Learning (CMTL).

This session is divided into four episodes that arise from using Schoenfeld model (1998a; 1998b; 2000): We observe how the teacher uses a proposed activity from a problem-solving perspective to introduce the basics of the topic: the polygon concept [Episode 1]. The activity is planned for the student to investigate and construct the meaning of this concept. The material used is a card where several flat figures are drawn (open and closed). This activity consists in the observation and analysis of the properties and elements of the given figures, in order to find a definition of polygon [Episode 2], through the general consensus where ideas are justified, arguments are requested on the ideas of others, the ideas of others and their own are analyzed, justified criticisms are accepted and the thought is completed with the contributions of others, to finally arrive at consensual agreements [Episode 3]. It concludes with the writing of the definition by each child (the definition that suggests what was worked on in the activity) [Episode 4].

\section{Episode 1 - Presentation of the Activity}

The teacher begins the class by explaining the structure of the work: first, each student will think about it individually, noting whether or not it is a polygon and thinking about why it is or is not a polygon. He seems to 

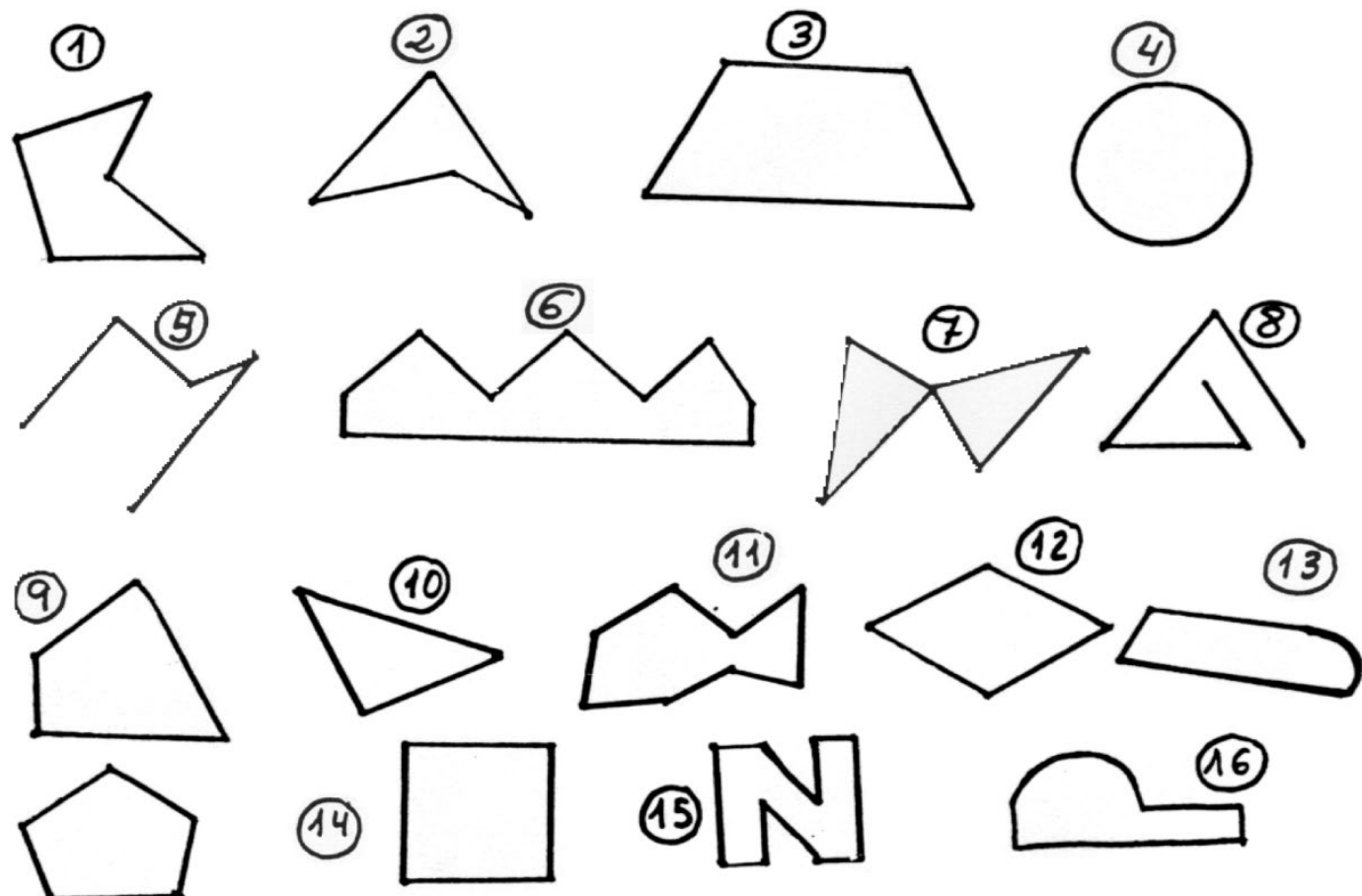

Figure 2. Images used by teacher

know that the comparison procedure is necessary for the identification of qualities, so she insists that students reflect on the properties and elements of the figures [KMT1]. Submit the form in Figure 2.

The teacher tries to take advantage of previous learning and experience to link previous knowledge with the purpose of the session (definition of polygon). We can see it in the lines: We're going to look at them for a little while and we're going to try to discover which of them are polygons, you remember the polygons, right? [...] Well, there are some that are polygons but there are others that are not. Then let's see if we remember or not... [V1. 6-14]. Teacher seems to know that this mathematical content has its own characteristic associated with the forms of learning by students [KMT2]: they have to find out what differentiating aspect exists between the figures and what aspect they have in common to define polygon. The intention is clear: to value and use previous experiences and learning, on which to build new ones. The role it gives to students is clearly marked, since they are the ones who will have responsibility for control in their learning process [E26], as well as in the search for answers to the question posed by the teacher [I23].

She insists that it is necessary to justify why it is or is not a polygon. Emphasis is placed on the student analyzing and making explicit the properties he is considering and arguing (but you know that it is not enough to say: "the number such a yes, or the number which is not ", but that it is necessary to say: "the number such a yes because..." or "no, because..." If it is or not, but also to say why it seems to you that it is or why it seems to you that it is not [V1]. 18-21]). She seems to know, justifiably, the properties and elements of the polygons that will serve him to corroborate the definition given by the students [KoT1], so he is emphasizing the role of justification in mathematics by demanding the reason for his statements [KPM1].

After a short waiting period, she enter more precise instructions for the work, which will force the characteristics of the polygon definition such as: closed, polygonal line, consisting of a single related component. These elements are relevant attributes of polygons (those that contribute to the definition), and also variants in figures that are polygons, that is, irrelevant attributes such as different number of sides, concave and convex, regular and irregular, with equal and unequal sides and finally incorrect attributes, such as open figures. The selection of these images has been made intentionally by the teacher, considering these three types of elements and considering the difference between definition and image of the concept. The choice of rich images, which include relevant, irrelevant and incorrect attributes with respect to the definition of polygon, highlights aspects of their knowledge of differentiation between definition and image of the concept [KMT3]. She also knows the properties and elements of the polygons [KoT1] that will be used to define it. Finally, she re-emphasizes the importance of having arguments, that one has to convince with reasons. It is also necessary to accept the arguments of the comrades if they convince you. It tries to make the student aware of the importance of what he does and why he does it constantly [I24]. 


\section{Episode 2 - Work of the Students}

During the individual work, the teacher continues to give weight to argumentation. Help children who don't remember what a polygon is, with a previous experience (the study of polyhedrons) so that from here they can reconstruct their idea of polygon. On that occasion, they classified geometric bodies according to different criteria that the children themselves said. "We put them here in the center, Mari, here in the center we put all the geometric bodies. And someone said: we are going to make the group of all the geometric bodies that are formed by polygons. And we started making groups. And there were some that had polygons of a single class and there were others that had polygons of several classes. One of them was that their faces were formed by polygons [V1. 65-72]. She gives the guidelines of that activity, hoping that in this way the students will "revive" it and be able to recover with it some images that will lead them to analyze the idea of polygon. We can observe that it seems to know that the content that is currently working and those that are at the base of its learning [KSM1] are related (relationships between the concepts of flat and threedimensional shapes), as well as the role that flat forms play in the composition of three-dimensional objects (polyhedra are formed by flat figures), for this it makes use of the identification of different qualities or attributes.

She asks to the children who have taken revolution bodies if their faces are polygons or belong to the other group they made (round geometric bodies). He knows that geometric bodies are composed of round and polyhedrons [KoT2] and his knowledge of the strategy of remembering polygons from geometric bodies [KMT4] is part of his knowledge of teaching. Finally, she asks them about which polygons their faces are: Do you have any? (A child holding up his hand with a geometric body. Then show it to everyone. That is a geometric body formed by polygons! What polygons form that geometric body? [V.1 140-159]. To which the child replies that it is made up of hexagons, giving the teacher the go-ahead (assent). We can see that he knows that polyhedrons are bounded by polygons and recognizes the type of polygons that form it [KoT3].

The students intervene by providing these characteristics and the elements: it has four sides, four vertices and four angles. These characteristics are an identification of the qualities of the figures they observe (shape, sides, parallelism and perpendicularity) and although in some cases they are redundant, they are all accepted. She seems to know the conceptual structure of the elements that make up the polygons [KoT4], and the teacher also asks the students to specify with expressions the concepts they have studied before (such as "perpendicular drying lines"). What were the lines called those lines that when they crossed each other formed four right angles? The teacher, from her knowledge, is forcing the student to use a certain vocabulary, which is precise in the mathematical content they are working on [KFLM1].

\section{Episode 3 - Pooling of Work}

She continues to deepen her understanding of how concrete students are when they need and use language, because a student tells her that the lines have little space. I don't understand. What do you mean, open? I think he's saying they're not, the angles that are formed, they're not all outward (and he makes the signal $\triangle$ with his hands), but some are inward (and he makes the signal V/) [V.1 314-322], On this occasion she demonstrates a knowledge of the types of angles that form the figures [KoT5], through the identification of the concave and convex angles. The information mobilized in the classroom is validated by the group and the teacher, promoting students' reflection and assuming responsibility (by the students) when judging the appropriateness of their ideas [I27]. Mario asks about whether figures with curved sides are polygons, to which the teacher replies that they are not. We can affirm that the teacher knows that the polygons do not have curvilinear sides [KoT6].

\section{Episode 4 - End of Session}

Faced with the last doubts, she proposes that each individual should write his definition of a polygon. In this way, he introduces a stop here to explain what definition each one is handling and to reflect on the characteristics he considers and those that meet the given figures. We can affirm that the learning has taken place through a small investigation planned by the teacher to use this definition in subsequent sessions [I2]. It seems that she is aware of the difficulties that her students have in uniting a series of characteristics such as the definition of polygon [KFLM2], and tries to drive the institutionalization of learning through the explanation of the different definitions, where individual reflection plays a relevant role. 


\section{DIAGRAM OF MTSK AND CMTL}

\section{Concepts as an Aid to Find Relationships between Elements of the MTSK Subdomains in V1}

The most important concepts observed in this session are two. Firstly, with regard to Methodology: The teacher seems to have organized the process that will lead the student to acquire specific knowledge through research [I2], and secondly, the conception of school mathematics: Both the acquisition of concepts and the development of procedures and the promotion of positive attitudes towards the subject itself, school work in general and as a citizen are of interest, with the subject matter and school work determining the specific weight of each of the abovementioned components [I8]. The knowledge related to these conceptions is several: on the one hand, the objective of the session is conceptual (define polygon and list its elements) [KoT7], and students are expected to apply the definition to the identification of figures (distinguish in a set of figures which are polygons). We can interpret that the teacher uses her knowledge of Mathematical Practice [KPM1] in the very procedure of defining (clear, ordered and precise expression), knowing what a definition is and what its characteristics are, because she knows how knowledge is explored and generated in mathematics and what are the elements with which mathematics is done. On the other hand, the conception [I2] is related to his knowledge of the activities that are most potent for students [KMT5].

Another aspect to highlight is the reflection of mathematics that wants students to learn: mathematics with meaning, conceptual (as opposed to mechanics). There is also an interest in focusing on students acquiring procedures of how to arrive at the mathematical definition: expressing themselves with order, clarity, precision, defining abstracting the fundamental and essential characteristics, distinguishing between elements and qualities or properties. We can see how Inés makes the student aware of what it means to construct a definition, what characteristics it must fulfil, what are the parts of the definition of polygon and what is contained in the definition [I24]. It is clear here how awareness of what is contained in a definition enhances an analysis of the definition of the polygon itself. Thus, the teacher seems to know what characteristics some of the elements of mathematics have, in this case: what is a definition [KoT7].

In his own description of the presentation of the activity to the students, she emphasizes what it means to take up what was worked on. It is important in the process of arriving at a definition that students justify the ideas that lead them to consider a figure as polygon or not (one objective is to justify the inclusion or exclusion of the group, and its associated content). There seems to be a relationship between their conception of learning where it is important for the learner to communicate and argue their opinions [I15], and their knowledge of how mathematics is done [KPM1].

At the end of the session, the teacher is aware of the difficulties that her students have in uniting a series of characteristics such as polygon definition [KFLM2], where she reminds them of a recent situation in which they distinguished and used the idea of polygons (when working with geometric bodies), causing the students to look for and use their previous learning. This supposes from the perspective of the teacher, she changes in the foreseen development of the activity and it is his knowledge about the activities that are more powerful for the students [KMT5], which leads to the institutionalization of learning through the explanation of the different definitions, where individual reflection plays an important role. This reflection on characteristics can be considered, comparing those of the given figures, as a strategy in which learning has taken place through a small research that has been planned [I2]

On the other hand, the teacher's conception of the role of the pupil has a great presence, for example, at the beginning of the session, where the teacher knows that the learning of the concept of polygon and its definition has its own associated characteristic of learning by the pupil [KMT2]. The intention is clear: to value and use the students' experiences and learning so that they can make new ones.

The teacher's knowledge of the definition of polygon [KoT7] and the situation it presents to the student where she must become aware of what she is doing and what she is doing it for [124], is clearly marked, since they are the ones who will have responsibility for control in her learning process [E26], as well as in the search for answers to the question posed by the teacher [I23].

Later, in small group work, the teacher's emphasis on social learning (the role she gives to the student) where they learn from each other is clear. It highlights here how they have to reach agreement, summarise and conclude.

Due to the number of descriptors found and used, it has been decided to include a table summarising all of them as an appendix. See at the end of the document (Appendix). 


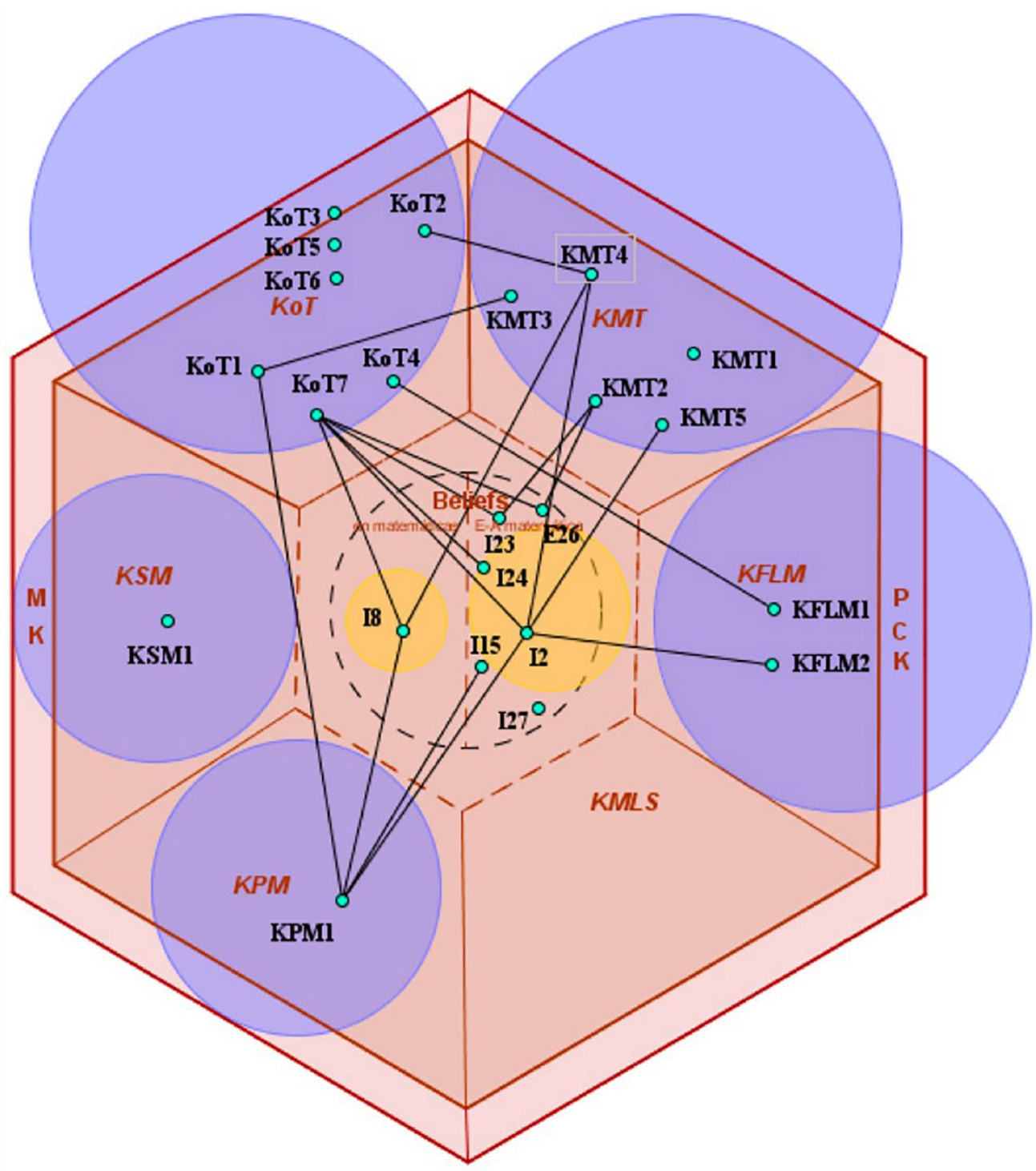

Figure 3. Graph of internal MTSK relationships

\section{DISCUSSIONS}

As Stylianides and Delaney (2018) assert, the notions of knowledge and beliefs of mathematics teachers have been conceptualized in multiple ways in literature. In this paper we have presented a form of them. However, despite these different conceptualizations, we agree with these authors that the knowledge and beliefs of math teachers are important factors to consider in the study of classroom instruction as well as in other aspects of teaching. These factors that they mention are clearly differentiated in the objectives that we propose for this research: Identify and understand elements of the different subdomains of the teacher's MTSK in relation to the teaching of polygons, as well as the possible relationships between these subdomains. Based on the detailed analysis of the data, knowledge components for each subdomain of the MTSK model have been identified. It can be confirmed that the knowledge of the teacher, especially in three subdomains and their relationships stand out: Knowledge of Topics (KoT), Knowledge of Features of Learning Mathematics (KFLM) and the Knowledge of Mathematics Teaching (KMT).

Regarding knowledge of the Mathematical Knowledge (MK), it has been identified that the teacher knows the concepts and procedures associated with working with polygons, and specifically, the classification of flat figures. This knowledge is in continuous interaction with the other subdomains which is a prominent aspect of her work as a teacher since it plays a very important role in her practice, in the aspects she works on or decisions to go into detail on a specific topic, as in the case of the concept of angle. This going into detail on different elements of the subject demonstrates a wide field of knowledge. 
Regarding her Pedagogical Content Knowledge (PCK), it is evident that the implementation of the problem solving perspective is the main source of work with which the teacher intends to teach. In this way, the difficulties she perceives in this unit make her aware of the limitations that students may have about the concepts they are working. A clear example of this is the prototypical examples of flat figures that she uses. These difficulties are expected by the teacher, and their resolution ranges from using materials to support her teaching, to using elements for a more dynamic geometry (superposition of angles), or the classification of triangles allowing movement to classify them. Her knowledge of learning is not just a question of definitions and images that students have to learn. She sets out teaching situations in which geometric construction is a fundamental pillar.

The other subdomains of knowledge, although there are not as many manifestations as those described above, are fundamental. An example of this is how her knowledge of mathematical practice influences the entire didactic unit, since the importance of and how she organizes the construction process of the polygon definition is a reflection of her mathematical practice.

It can be confirmed that there are different relationships between the subdomains as explained in the previous section. As in Flores, Escudero and Aguilar (2013), some relationships between subdomains were set out (KFLMKMT, KoT-KPM, KoT-KFLM or KoT-KMT). These relationships have served as a fundamental pillar to understand the specialisation of the teacher's knowledge. In our case, the following objective that was selected has been of help in discovering these relationships (to detect the conceptions about Teaching and Learning mathematics and its relationship with the subdomains of specialised knowledge for the teaching of mathematics by the teacher). The idea that conceptions guide the analysis, in the sense that a certain conception is presented and is then connected with elements of knowledge of the subdomains, has enabled us to understand knowledge in a more complete way, allowing us to reflect on the nature of conceptions. Thus, Figure 3 provides us with a general understanding of the knowledge revealed by the teacher in her classroom. In line with Conner, Edenfield Gleason and Ersoz (2011), the beliefs that the teacher has expressed throughout the session have remained stable, as this study did not attempt to see a development in them. Confirming the beliefs they put in the foreground are those that put the activities and understanding of the students first.

\section{CONCLUSIONS}

We can affirm that the theoretical framework used have served as excellent tools for analysing professional knowledge as well as concepts on the teaching and learning of mathematics. It should be mentioned that, throughout this research, an attempt has always been made not to lose the integrated vision of the knowledge that the teacher has displayed in the classroom. Despite having to use instruments that parcel up professional knowledge and the teacher's conceptions in an analytical way, it is concluded that the richness of these manifestations qualifies us to understand the subdomains of knowledge.

We can affirm the Mathematics Teacher's Specialised Knowledge (MTSK) model is a theoretical proposal that recognizes the potential of describing a body of knowledge that only makes sense for the mathematics teacher, and is, in turn, a methodological tool for analyzing different mathematical practices through its categories. This model eliminates the problems of delimitation between subdomains that other knowledge models have defined, by assuming the specialised character for all the subdomains. This is an advance with respect to other models, and model considers the beliefs of the teacher at the core of the model; the fully integrated study of the relationships between beliefs and knowledge is an advance.

The MTSK model has allowed us to analyze in depth the nature of the examples and counterexamples in this specific case, being a potential for possible use in teacher training. In Figure 3 we can see the large circles, which show us which contents on polygons seem important for the training of teachers. For example, KPM1 seems to be a nuclear knowledge throughout the session, both in terms of the number of relations that start from it and the importance it has throughout the session. On the other hand, one knowledge to highlight is KoT4 and KoT7, this knowledge on the subject we have analyzed, continues in the line of Tsamir, Tirosh, Levenson et al,. (2015) where teachers were asked to define figures and to identify several examples and not examples of the figure. The teachers' use of correct and precise mathematical language and the reference to critical and non-critical attributes were also investigated. All of the above helps us to characterize the key dimensions of the quality of teachers' mathematical knowledge for teaching and the connections between these dimensions, as Chinappan and Lawson (2005) pointed to the lack of such characterizations.

Finally, this research is useful for future research in the area of mathematical education that would like to carry out an in-depth study of the treated aspects. Numerous research studies have been documented in the research literature, but there are few where such clarified relationships can be found, and where both complement each other. 


\section{REFERENCES}

Ball, D. L. (1990). Prospective elementary and secondary teachers' understanding of division. Journal for Research in Mathematics Education, 21, 132-144. https:// doi.org/10.2307/749140

Ball, D. L., Lubienske, S. T., \& Mewborn, D. S. (2001). Research on teaching mathematics: The unsolved problem of teachers' mathematical knowledge. In V. Richardson (Ed.), Handbook of research on teaching (4th ed.) (pp.433456). New York: Macmillan.

Ball, D. L., Thames, M. H., \& Phelps, G. (2008). Content knowledge for teaching: What makes it special? Journal of Teacher Education, 59, 389-407. https:/ / doi.org/10.1177/0022487108324554

Bassey, M. (1999). Case study research in educational settings. Buckingham: Open University Press.

Blumer, H. (1969). Symbolic Interactionism. Perspective and Method. Englewood Cliffs: N. J. Prentice Hall.

Carrillo, J. (1998). Modos de resolver problemas y concepciones sobre la matemática y su enseñanza. Huelva: University of Huelva Publicaciones.

Carrillo-Yañez, J., Climent, N., Montes, M., Contreras, L. C., Flores-Medrano, E., Escudero-Ávila, E., Vasco, D., Rojas, N., Flores, P., Aguilar-González, Á., Ribeiro M. \& Muñoz-Catalán, M. C. (2018): The mathematics teacher's specialised knowledge (MTSK) model. Research in Mathematics Education, https:/ / doi.org/10.1080/14794802.2018.1479981

Chinnappan, M., \& Lawson, M.J. (2005). A framework for analysis of teachers' geometric content knowledge and geometric knowledge for teaching. Journal of Mathematics Teacher Education, 8, 197-221. https:/ / doi.org/10.1007/s10857-005-0852-6

Climent, N. (2005). The professional development of the Primary teacher regarding the teaching of mathematics. A case study (Doctoral dissertation). Michigan: Proquest Michigan University. www.proquest.co.uk.

Conner, A., Edenfield, K. W., Gleason, B. W., \& Ersoz, F. (2011). Impact of a content and methods course sequence on prospective secondary mathematics teachers' beliefs. Journal of Mathematics Teacher Education, 14(6), 483504. https:/ / doi.org/10.1007/s10857-011-9186-8

Contreras, L. C. (1999). Concepciones de los profesores sobre la resolución de problema. Huelva: Universidad de Huelva Publicaciones. [Vol. I: 30]

Cooney, T. J., \& Shealy, B. E. (1994). Conceptualizing teacher education as field of inquiry: theoretical and practical implications. In J. P. Ponte \& J. F. Matos (Eds.) Proceedings of the eighteenth International Conference for PME, Vol II, pp. 225-232. Lisboan.

Davis, B., \& Simmt, E. (2006). Mathematics-for-teaching: An ongoing investigation of the mathematics that teachers (need to) know. Educational Studies in Mathematics, 61, 293-319. https:/ / doi.org/10.1007/s10649-006-2372-4

Ernest, P. (1988). The Epistemological Basis of Qualitative Research in mathematics education: A Postmodern Perspective. In A.R. Teppo (Ed.), Qualitative Research Methods in Mathematics Education, (pp. 22-39). Reston, Va: National Council of teachers of Mathematics.

Even, R., \& Tirosh, D. (2008). Teacher knowledge and understanding of students' mathematical learning and thinking. In L. D. English, M. B. Bussi, G. A. Jones, R. A. Lesh, B. Sriraman, \& D. Tirosh (Eds.), Handbook of international research in mathematics education (pp. 202-222). New York: Routledge.

Fennema, E., \& Franke, M. L. (1992). Teachers' knowledge and Its Impact. In D.A. Grouws (Eds.), Handbook of Research on Mathematics Teaching and Learning, (pp. 147-164). Reston, Virginia: NCTM.

Flores, E., Escudero, D.I., \& Aguilar, A. (2013). Opportunities offered by some scenarios to show evidence of MTSK. In A. Berciano, G. Gutiérrez, A. Estepa, y N. Climent (Eds.), Investigación en Educación Matemática XVII (pp. 275282). Bilbao: SEIEM.

Flores-Medrano, E., Escudero-Ávila, D., \& Carrillo, J. (2013). A theoretical review of Specialized Content Knowledge. In B. Ubuz, C. Haser, \& M.A. Mariotti (Eds.), Proceedings of the CERME 8 (pp. 30553064). Antalya, Turkey: METU and ERME.

Gess-Newsome, J. (1999). Secondary teachers' knowledge and beliefs about subject matter and their impact on instruction. In J. Gess-Newsom \& N. G. Lederman (Eds.), Examining pedagogical content knowledge (pp.51-94). The Netherlands: Kluwer Academic Publisher.

Kvale, S. (1996). Interviews: An introduction to qualitative research interviewing. Thousand Oaks: Sage.

Lincoln, Y. S., \& Guba, E. G. (1985). Naturalistic Inquiry. Beverly Hills, Ca: Sage.

Maasepp, B., \& Bobis, J. (2015). Prospective Primary Teachers' Beliefs about Mathematics. Mathematics Teacher Education and Development, 16(2), 89-107. 
Merriam, S. B. (1988). Case Study Research in Education: A qualitative approach. San Francisco, CA: Jossey-Bass Publishers.

Montes, M.A., Aguilar, A., Carrillo, J., \& Muñoz-Catalán, M.C. (2013). MTSK: From Common and Horizon Knowledge to Knowledge of Topics and Structures. In B. Ubuz, C. Haser, \& M.A. Mariotti (Eds.), Proceedings of the CERME 8 (pp. 3185-3194). Antalya, Turkey: ERME.

Mora, D. V., Climent, N., Escudero-Ávila, D., Montes, M. A., \& Ribeiro, M. (2016). Conocimiento Especializado de un Profesor de Álgebra Lineal y Espacios de Trabajo Matemático. Bolema: Boletim de Educação Matemática, 30(54), 222-239. https:/ / doi.org/10.1590/1980-4415v30n54a11

Pajares, F. (1992). Teachers' beliefs and educational research: Cleaning up a messy construct. Review of Educational Research, 62(39), 307-332. https:/ / doi.org/10.3102/00346543062003307

Philipp, R. A. (2007). Mathematics teachers' beliefs and affect. Second handbook of research on mathematics teaching and learning, 1, 257-315.

Ponte, J. P. (1992). Concepçoes dos professores de matemática e processos de formaçao. Educaçao Matemática. Lisboan: Instituto de Inovaçao Educacional.

Ponte, J. P. (2012). Estudiando el conocimiento y el desarrollo profesional del profesorado de matemáticas. In N. Planas (Ed.). Teoría, crítica y práctica de la educación matemática (pp. 83-96). Barcelona, Spain: Graó, de IRIF, S.L.

Rowland, T., Huckstep, P., \& Thwaites, A. (2005). Elementary teachers' mathematics subject knowledge: the knowledge quartet and the case of Naomi. Journal of Mathematics Teacher Education, 8, 255-281. https:/ / doi.org/10.1007/s10857-005-0853-5

Santos, L. (2002). A investigação e os seus implícitos: contributos para uma discussão. Actas del VI Simposio de la SEIEM: Logroño, pp. 157-170.

Schoenfeld, A. (2000). Models of the Teaching Process. Journal of Mathematical Behavior, 18(3), $243-261$. https:/ / doi.org/10.1016/S0732-3123(99)00031-0

Schoenfeld, A. H. (1998a). Toward a theory of teaching-in-context. Issues in Education, 4(1), 1-94. https:/ / doi.org/10.1016/S1080-9724(99)80076-7

Schoenfeld, A. H. (1998b). On modelling teaching. Issues in Education, 4(1), 149-162. https:/ / doi.org/10.1016/S10809724(99)80084-6

Shulman, L. S. (1986). Those who understand: Knowledge growth in Teaching. American Educational Research Association, 15(2), 4-14. https:/ / doi.org/10.3102/0013189X015002004

Stake, R. E. (2000). Case Studies. In Denzin, N.K. y Lincoln, Y. (Eds.), Handbook of qualitative research (435-454). Thousand Oaks: Sage Publications.

Stake, R. E. (2005). Qualitative Case Studies. In N.K. Denzin y Y.S. Lincoln (Eds.), The Sage handbook of qualitative research. Third edition (443-166). Thousand Oaks: Sage Publications.

Strauss, A., \& Corbin, J. (1994). Grounded Theory Methodology: An overview. In N.K. Denzin, \& Y. Lincoln, (Eds) Handbook of qualitative research (pp. 273- 285). Thousand Oaks, C.A: Sage.

Stylianides A. J., \& Delaney S. (2018). Pre-service Mathematics Teachers' Knowledge and Beliefs. In Stylianides G., Hino K. (eds) Research Advances in the Mathematical Education of Pre-service Elementary Teachers. ICME-13 Monographs. Springer, Cham. https://doi.org/10.1007/978-3-319-68342-3_15

Thompson, A. G. (1984). The relationship of teachers' conceptions of mathematics and mathematics teaching to instructional practice. Educational Studies in Mathematics, 15, 105-127. https:/ / doi.org/10.1007/BF00305892

Thompson, A. G. (1992). Teachers' beliefs and conceptions: A synthesis of the research. In D. A. Grouws (Ed.), Handbook of research in mathematics teaching and learning (pp. 127-146). New York, NY: Macmillan.

Tsamir, P., Tirosh, D., Levenson, E., et al. (2015). Early-years teachers' concept images and concept definitions: triangles, circles, and cylinders. ZDM Mathematics Education, 47, 497. https://doi.org/10.1007/s11858-0140641-8

Vasco, D. (2015). Specialized knowledge of the Linear Algebra teacher. A case study at the university level (Doctoral dissertation). Huelva, España: University of Huelva. http:/ / hdl.handle.net/10272/11901

Wilkins, J. L. M., \& Brand, B. R. (2004). Change in preservice teachers' beliefs: An evaluation of a mathematics methods course. School Science and Mathematics, 104(5), 226-232. https://doi.org/10.1111/j.19498594.2004.tb18245.x 
Zoitsakos, S., Zachariades, T., \& Sakonidis. C. (2015). Secondary mathematics teachers' content knowledge for teaching in two contexts: Interpreting versus managing didactically students' understandings. In Konrad Krainer; Nad'a Vondrová. CERME 9 - Ninth Congress of the European Society for Research in Mathematics Education. pp. 3296-3302, Prague, Czech Republic.

\section{APPENDIX}

\section{Summary of Knowledge and Conceptions Descriptors}

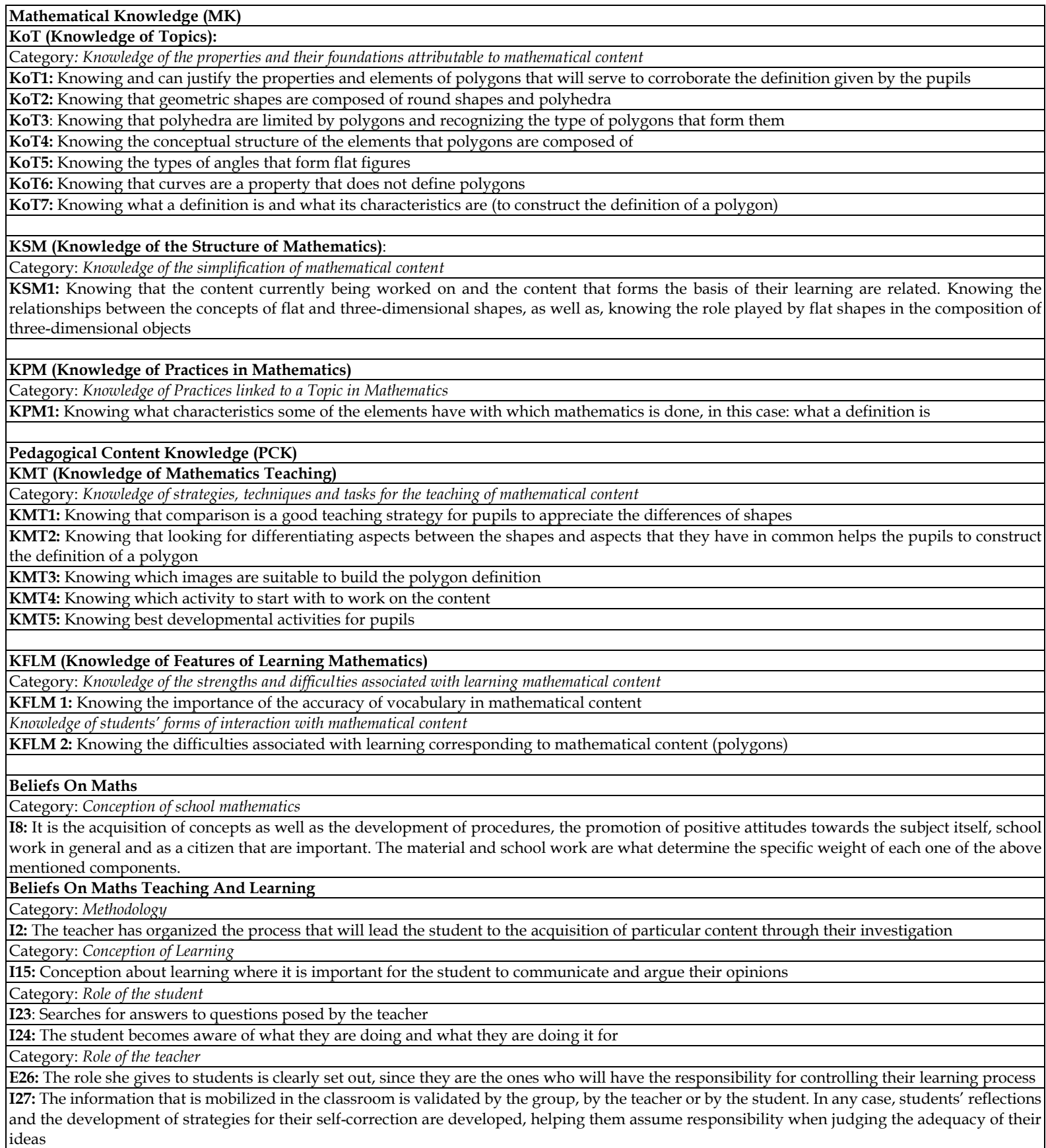

\section{http://www.ejmste.com}

